\title{
Introduction - Mental and Emotional Distress as a Social Justice Issue: Beyond Psychocentrism
}

\author{
HEIDI RIMKE \\ University of Winnipeg, Canada
}

KEYWORDS psychocentrism; psychiatrization; medicalization; mental distress; neoliberalism; social inequalities; social injustice; victim-blaming

\section{Introduction}

This special issue of Studies in Social Justice critically explores the complex relationship between social injustice, mental and emotional distress/difference, and the pathologization of individuals in contemporary neoliberal society. Our primary focus, as outlined in the "Guest Editors' Preface and Acknowledgments," is placed on critical theoretical and methodological approaches to studying and analyzing the power of medicine and psychiatry in modern society. The collective research trajectory aims to analyze the significant, and yet often overlooked, link between mental and emotional health/distress (private troubles) and social injustice (public issues) (Mills, 1959). The essays in this issue interrogate and challenge dominant "psy" discourses and practices with an emphasis on poststructuralist and intersectional approaches to social inequalities and social injustices. The special issue highlights the importance of the relationship between embodiment, social inequalities, the pathologization of difference and psy truths (Rimke, 2003).

Contemporary society has been colonized by the "psy complex" defined here as a hegemonic formation comprised of a loosely defined group of experts connected through their professional and social status, particularly psychiatrists, psychologists, psychiatric nurses, psychotherapists, psychoanalysts, and social workers. It is conceived as a heterogeneous network of agents, sites, practices, products and techniques for the production, dissemination, legitimation, and utilization of psy truths. 
Historically, the emergence of the psy complex occurs through the medicalization of morality in the 19th century (Rimke \& Hunt, 2002). Also, it is important to note that from the perspective employed here, the historical formation of the psy complex is inextricable with the emergence and maintenance of neoliberal culture where individuals are taken to be free and autonomous consumers responsible for their own health and illness or distress. Additionally, the psy complex produces the psy industry that emerged in concert with the rise of capitalist industrialization in North America.

The psy complex is problematized in this special issue by applying the notion of "psychocentrism," the view that human problems are due to a biologically-based flaw or deficit in the bodies and/or minds of individual subjects. Psychocentrism is itself a form of social injustice, where individual reformation rather than social and economic justice is promoted. Mental and emotional distress are thus taken here to be the consequence of societies built on systemic social inequalities that reproduce social injustices while profiting from them. The articles in one way or another analyze the adverse and growing reach of the psy complex.

Before defining neoliberalism and social injustice, and outlining a short theoretical history of the concept of psychocentrism, a brief note on the politics of language is necessary. Understanding the interrelationship between language, culture, power and social injustice is of paramount importance given that contemporary poststructuralist analyses examine the constitutive role discourse and knowledge play in the exercise of power and $\mathrm{ab} /$ normalization of human life. Thus, to move towards a social justice model of mental and emotional life, it is vital to examine the ways that language can contribute to, or counteract, social inequalities. Following the important sociological work of David Pilgrim (2003, 2005), the language deployed throughout this special issue prefers to use "mental distress" over "mental illness," the latter being stigmatizing, and therefore largely counterproductive. The term mental illness is also problematic because it gives the appearance of scientific proof and medical consensus, which has not (yet) been achieved. Critical approaches to the psy complex have rejected the psychocentric hypothesis on theoretical, empirical and ethical grounds since the 1950s (Foucault, 1954; Goffman, 1963; Kirk, Gomory \& Cohen, 2013; Smith, 1990).

A now significant body of scholarship argues and demonstrates that the concept of mental illness is of dubious scientific validity. Many scholars have argued that tautology, not science, is invoked regularly to warrant the legalized and unethical control of people who are seen to offend, threaten, and frighten. All efforts to date to define mental disorder have been flawed on a number of counts (Kirk et al., 2013; Pilgrim, 2005; Turner \& Edgley, 1983). It is in this critical vein that the articles in the special issue challenge rather than fortify the psy complex and psy industry. Following the pioneering feminist sociology of Dorothy Smith $(1987,1990)$, these critical 
analyses are on guard against Eurocentric, androcentric, masculinist, positivist social thought that serve the interests of dominant social groups at the expense of the dominated group.

Neoliberalism can be understood as a series of pro-market and procorporate policies that seek to integrate state and market operations to benefit the interests of transnational corporations and the wealthy. Increasingly, neoliberal governmentality manages human subjectivities as an ensemble of social forces that both construct and reinforce individualization and privatization. Evaluated on the basis of self-control expressed through a market rationality where health and illness are commodified, depoliticized and individualized, modern subjects are treated and viewed as either successful or failed consumers of mental and emotional health. As this special issue establishes, the early $21^{\text {st }}$ century is defined by pathological individualism, where health is seen as something to be attained or managed by industrious, virtuous, and productive neoliberal citizen-subjects.

Social justice can be understood as the extent to which a society ensures an equal distribution of resources and opportunities in the political, economic, institutional, and social realms. Further, social injustice should be understood as having undeniable mental and emotional dimensions. The focus of a social justice approach is based on the conviction that all individuals and groups within a given society have universal human rights, including an equal opportunity to participate in the educational, economic, institutional, and social freedoms and responsibilities valued by the community. Those concerned with social justice work for structural change to increase social opportunities and improve social conditions of those who are politically, economically and socially disadvantaged and marginalized.

\section{Psychocentrism: Historical and Theoretical Summary}

The conceptual career of psychocentrism began to emerge in 1996 as part of my master's work, which critically analyzed self-help literature as a form of neoliberal governmentality (Rimke, 1997, 2000). My doctoral dissertation continued the study of psy discourses by documenting and analyzing the invention of normality primarily through the doctrine of moral insanity (Rimke, 2005). The dissertation argues that medicalization and psychiatrization of immoral desires and conduct should be understood as shaped in the $19^{\text {th }}$ century by a hybridization of Christianist morality and Enlightenment positivism, forming the spring-board for what eventually came to be referred to as abnormal psychology specifically, and psychiatry more generally.

Over the course of time, my conceptualization and use of the notion continued to develop in different social and intellectual contexts. Its purpose is to provide an alternative or counterhegemonic reading to dominant psy approaches by providing a critical analytical tool. It thus offers a conceptual 
approach to critically examine and analyze psy discourses and practices in their intricate, specific, and universalized machinations. A key aim of applying the concept in this special issue is to attend to and emphasize the broader structural factors at play in the relationship between mental and emotional distress and social injustice.

In the last 10 years of research and writing, I have applied the concept of psychocentrism to different social problems and discourses in contemporary society: individualistic theories of crime and criminality (Rimke, 2011); cannibalism and the not criminally responsible due to a mental disorder (NCRMD) defense (Rimke, 2010a, 2010b); the criminalization and pathologization of terrorism (Rimke, 2012, 2016); and, the growth of the culture of therapy in neoliberal capitalism (Rimke \& Brock, 2012). While the concept initially encompassed six basic characteristics, it has been expanded to include a total of 10 characteristics (which may or may not operate simultaneously) as follows:

1. reductionism: reducing the complexity of human experience and problems to simplistic explanations, usually by advancing the modernist view of the self-contained body-mind model;

2. determinism: claiming that human conduct and experience are determined by their "natural" bodily make-up (genetics, hormones, neurochemical, etc.);

3. essentialism: the view that humans are essential categorical or personality types; that groups of individuals possess an innate characteristic or essence that is permanent, unalterable, stable, static, etc.;

4. presentism or ahistoricism: historical amnesia or the analytical disregard for history and its role in constituting our present understandings of our selves individually and collectively;

5. naturalism: viewing humans as natural rather than social or socially located, shaped, and produced;

6. ethnocentrism: the assumption that one's cultural practices and beliefs are normal and thus superior than other cultural practices and ways of being in the world;

7. double-standards: a set of principles unequally applied to two or more different groups. An example is the gendered double standard of sexuality where women are cast negatively while men are represented positively for the same sexual conduct;

8. victim-blaming: holding individuals and groups responsible for their own fates or negative outcomes, including their experience of mental and emotional distress or traumatic life experiences, usually by placing themselves in high risk situations;

9. positivism: using the prestige and veneer of science to construct mental illness as analogous to the same physical markers found in physical illness; 
10. pathological individualism: the modern master status of the person defined in terms of ab/normalization and/or self-categorization and/or expert classification.

The notion of psychocentrism provides a framework to investigate the ways in which neoliberal populations are governed according to psy knowledge. It also draws our attention to expert discourses that minimize or negate the deleterious effect of social inequalities. Psychocentrism is based on on the human deficit model, while obscuring societal deficits and social relations of power that often underlie and contribute to human struggles and difficulties. It is important to study and deconstruct the ways that social injustices such as sexism, classism, racism, heterosexism, colonialism, ableism, ageism, adultism, sanism, and so forth, operate in, and intersect with, mental health problems. The interlocking axes of oppression and inequalities are inimical to human life and thus need to be taken into account when analyzing contemporary mental health in/justice.

Psychocentrism largely rests upon the epistemological prestige of positivism derived from the prominence of natural sciences. In particular, the claim that abnormality can be explained scientifically by isolating causal evidence for differences amongst individuals is especially problematic. Psy discourses are contentious and problematic for many reasons: classificatory ambiguity, lack of physical/organic medical evidence, the highly subjective nature of notions such as normal and abnormal, the long, political and controversial use of psychiatric practices and interventions (electroconvulsive shock therapy, lobotomy, leucotomy, drugs), and conflicting empirical data, render the ethical and intellectual status of the psy complex scientifically and socially problematic.

Another problem of the dominant biomedical paradigm is that it remains strictly at an individualistic level, whether the abnormality is conceptualized as the result of faulty thinking, biochemical failures, or defective genes. Personal deficits are explained as the by-product of any one, or a combination of, heredity, neurotransmitters, hormones, and so forth. Constructing a science of psychiatry has proven problematic and elusive, yet billions of dollars each year are spent researching, promoting, consuming and advertising it. After over 100 years of the hypothesis that abnormal function and activity in specific brain circuits are the cause of mental illness, not one single biological marker for a single psychiatric disorder has been identified to validate mental illness as a medical disease (Epstein, 2016). The assumption that the brain secretes mental illness like the kidney secretes urine (Noll, 2011, p. 68), and that the right scientific tools can unlock such hidden secrets in the individual body or mind, have yet to be proven. No etiology or cause has been determined for any so-called psychiatric illness or disease as catalogued in the Diagnostic and Statistical Manual, also referred to as the psychiatric bible, now in its fifth edition (APA, 2013). 
The cumulative pain and suffering due to inequalities takes its toll on individual minds, hearts, bodies, communities - and far more on some social groups than others. This special issue acknowledges the violent practices of patriarchal, colonialist, capitalist society that result in trauma, pain, and harm both directly and indirectly, primarily or vicariously. The opposite of oppression is not only feelings of peace, stability and support, it is also the privilege to be oblivious to others' social and economic problems. To quote Ursula Franklin, "peace is not the absence of war. Peace is the absence of fear. Peace is the presence of justice" (2014, p. 36).

\section{Psychocentrism, Neoliberalism and the Culture of Therapy: A Critical Social Analysis}

Modern individuals face a multitude of social challenges and problems. Supra-individual factors at the root of human struggles include: precarious employment or joblessness; lack of secure housing; mental, emotional, physical, sexual, spiritual, racial, and digital violence; financial problems; and the trauma and complication of climate disasters. The failure of connecting social structural forces in people's lives at best results in a weak theoretical link between mental and emotional distress and social injustice. At worst, it uses psy discourses to blame the marginalized and underprivileged for their socially produced suffering. Viewed from the depth and magnitude of global human suffering, psychocentrism promotes naive or superficial fixes to macrological social and economic problems. Furthermore, the intersection of multiple social factors that structure access to resources, assistance and support, arguably, are key components in feelings of security, peace and a sense of well-being, the lack of which often lie at the base of human problems.

In the current historical period, the "neoliberal self" is encouraged by a market-driven, consumer culture that normalize the notions of health, happiness, well-being, etc., as accomplished only or primarily through

consumption practices. Another indication of psychocentricity is the overuse of the word "normal" itself - historically we would have used words and terms such as "usually," "typically," or "on average." We see the promotion of neoliberalism in our cultural and economic systems, which assume that all people are motivated by "rational self-interest" as homo economicus, defined in terms of money and resources. Such an assumption disproportionately benefits the interests of corporate elites and the privileged classes.

Psychocentricity dovetails seamlessly with the values of neoliberalism by giving the appearance that "normalcy" is desirable, concrete and attainable. From this perspective, personal success is marketed as readily accessible to everyone and anyone, regardless of income level, educational background, geographical location, sexual identity, religious affiliation, and so on. From a critical social scientific perspective this is very problematic. Pathological 
individualism encourages us to close ourselves to others. It is done partly for protection out of fear and partly for expediency, but it is a decision to see ourselves as cut off from others as a basic social fact of life. Psychocentrism prevents compassion, empathy and connectedness, and it prevents us from feeling a sense of ethical responsibility to those without voices, networks, and resources. The imperatives of governmental policies to ensure basic essentials for healthcare, education, and retirement security or legislation to protect consumers, environment and workers thus falls to the wayside as psychocentrism increasingly colonizes neoliberal culture.

The growing material, mental, physical, and emotional tensions and struggles of contemporary society are expressed in multiple ways. The many harmful effects of white supremacist, capitalist, patriarchy result in isolation, violence, anxiety, anger, apathy, repulsion, depression, and suicide. Although individually experienced, such human experiences must be placed within the context of social life and structures. Human lives are affected by growing economic deterioration and austerity, as well as social conflicts based on axes of age, sexual orientation, class, gender, physical appearance, familial ties, educational attainment, religious status, racialization and ethnicity, political repression, and other socially created insecurities. These include the lack of affordable and stable housing, growing under- and unemployment, the erosion of pensions, rising food and energy prices, and toxic work environments, which negatively affect too many members of society in numerous troublesome and troubling ways. Yet, the resounding messages provided by psy experts imply that people's struggles are strictly personal internally produced - as though our experiences in the world were somehow separate and distinct from the social conditions that shape, produce, and order those experiences.

Today, the psy industry is very big business with mass marketing for drugs and self-help strategies that encompasses all aspects of human life. This is a massive and growing industry, with estimates ranging from 35 to 50 billion dollars in profits annually for the self-help, and mental health and addictions fields alone. Clearly, the industry of pathological individualism is the leading and best-selling genre in North America. Although it is very difficult to obtain exact numbers from the corporate drug industry, several scholars have documented the dramatic rise of psychopharmaceutical prescriptions as the stock response to mental and emotional distress. In 2010, the top 10 Fortune 500 companies - all pharmaceutical - made more profits than the other 490 companies combined (Rimke \& Brock, 2012). The practice of polypharmacy has increased substantially over the past two decades, creating its own set of problems and consequences where "Big Pharma" is an economic and social empire (Moncrieff, 2009). Other intellectuals have critiqued the rise of a "pharmacracy" (Szasz, 2003) or "pharmageddon" (Healy, 2012) as a result of the psy industry.

Therapeutic culture has created an enormously profitable economic sector, from self-help books to the dramatic growth of pharmaceutical companies. 
Many critics argue that pharmaceutical companies - rather than evidencebased research - are the modern day driver behind growing psychiatric diagnosis. It is thus no coincidence that the psy complex has become the most lucrative industry on the planet. Further, when psychocentric research is funded by those pharmaceutical companies themselves, significant ethical and epistemological dilemmas arise, yet fail to be addressed by the state (Rimke, 2010c).

Given its staggering commercial profits, the social influence and effects of the psy industry in wider society cannot be overstated. The increasing focus placed on individual responsibility has been occurring simultaneous to the dismantling of public health care and social services, forcing individuals to absorb structural deterioration. Presumably, such therapeutic acts are equally available to all people, everywhere regardless of socioeconomic position or geographical location? What appears personal is socially proscribed and either internalized as a good citizen-subject or resisted as a bad, ungovernable citizen-subject. For, after all, even the most private self-examination is tied to social systems of valuation, imposition, judgement, and regulation (Foucault, 1988).

Psychocentrism presupposes a very specific type of individual - primarily one with the economic means and cultural competence to own, use and have the time and resources to engage with psy expertise. As a result, many are systematically excluded from this form of health management as not all can be competent or capable "consumers" of health and wellness given the rampant poverty in neoliberal society. Human health and illness involve social factors that are dismissed or marginalized within contemporary biomedical approaches, which therefore fail to fully capture the complexities of human being, subjectivity, injustice and social life. Research indicates that there is an indisputable social dimension to health/well-being that cannot be reduced to, and explained at, the individual level alone. Quality of life is likely the best indicator for mental and emotional health - secure housing, stable income, leisure time, social networks, community membership, meaningful relationships - thus demonstrating the social bases of human life.

\section{Overview of Contributions to the Special Issue}

The authors contributing to this special issue apply the notion of psychocentrism to frame and analyze different aspects or problematics of the contemporary psy complex. Critical of dominant claims that lack evidence and/or ignore social inequalities, these articles emphasize and examine social relations of power and inequality that underlie human suffering. Using psychocentrism as a critical epistemological framework to challenge dominant psy assumptions and discourses, the authors use a social justice lens or analytic to produce critical mental health scholarship. This necessarily entails an analysis of the ways that stigmatization, discrimination, 
inferiorization, and dehumanization are explicitly tied to the problem of social injustice.

The overall aim of the special issue is to chart and analyze the social and political relations at the heart of pathological individualism that is maintained and reproduced through psychocentrism. The articles provide critical, reflexive, interpretive, qualitative methodological approaches to critical research, theory, and analysis (Rimke, 2010c). Each analysis draws on critical theoretical and methodological approaches, such as performance ethnography, critical discourse analysis, content analysis, participant and naturalistic observation, interviews and focus groups, and therefore this issue provides multiple frameworks for critically analyzing the place and effects of psychocentricity. What is typically or normatively seen and represented as individualistic and pathological, is instead understood as historically constituted, culturally produced, politically oriented, and socially maintained. The essays demonstrate that experiences of emotional suffering and mental distress manifest within wider historical, economic, cultural and political contexts both locally and globally.

Critical mental health research examines not just how mental health issues are framed, named and studied, and how mental health treatment, care and supports are conceived and implemented. It also questions the psy logic of advanced neoliberal, patriarchal, and postcolonial societies, with its noxious effects on individual and collective mental and emotional health. The contributions examine the problematic bases and effects of traditional psy discourses and practices of power in six substantive areas in critical mental health research: the growing popularization of mental health first aid discourses; autism and opposing social movements to either fix or accept autistic people as they are; sanism or discrimination against those diagnosed as mentally ill as a form of unjust research; racism, incarceration and Indigenous youth suicide; problematic eating patterns, sexism and female body image; and, homelessness and poverty as pathology. All of these approaches apply the concept of psychocentrism in their own ways. These articles also reject the neoliberal pluralist notion of social power as equally exercised by all individuals and social groups. Further, they challenge the view that positivist knowledge production is socially neutral and universally beneficent.

Jan DeFehr provides a timely, critical analysis of the popularization of Mental Health First Aid (MHFA) discourses, which are increasingly applied to define social catastrophes, such as the suicide crisis in Indigenous communities, as psychiatric emergencies. The article shows that the globalized movement to pathologize human distress ignores or occludes social and historical sources of pain and suffering. She outlines the highly problematic MHFA model that seeks to train everyday people or non-experts to recognize the so-called signs of mental illness, providing further support for the spread of neoliberal psychocentric styles of thought. This is expressed forcefully in the conclusion where DeFehr points out that the training of 
neoliberal subjects as "citizen-diagnosticians" creates a new form of moral policing, which undermines social structural change that would ameliorate much social injustice.

Julia Gruson-Wood's article examines the politics of the dominant behavioural therapy (ABA) used to train and discipline both therapists and people with autism. She addresses the disagreement between those who seek to cure autism and those who seek accommodation for those who have a diagnosis or self-identity as autistic. The psychocentric suggestion that autistic people have a "natural" way of being fails to understand that all people are socialized or socially shaped, disciplined, normalized and subjectified. Gruson-Wood critiques the dominant biomedical approach by analyzing the ABA framework, philosophy and strategies. She highlights the exceedingly controlling and self-governing aspects of ABA training and ABA experts/trainers.

Stephanie Leblanc and Elizabeth Anne Kinsella's article provides an important discussion and analysis of the problem of sanism, a serious form of epistemic injustice. They challenge as highly questionable any type of psy knowledge that does not take into account the views and experiences of service-users, survivors and ex-patients as integral sources of information. Traditional, expert psy approaches objectify and subjectify those who struggle with mental and emotional distress. Drawing on feminist research and mad studies scholarship, they provide an important theoretical analysis of the relationship between sanism, epistemic injustice, and psychocentrism.

Mandi Gray's essay analyzes an inquest into the suicides of two Indigenous female youth while they were imprisoned at the Manitoba Youth Centre. Her paper challenges the view that the inquest is a neutral and objective factfinding project designed to help or protect incarcerated youth. The official legal or medical texts treat the suicides as a consequence of mental illness, rather than the result of a matrix or intersection of multiple social inequalities due to social factors. Viewing suicide as an individual pathology conveniently ignores the social, political, economic, and colonialist violence underlying Indigenous children's desire to die or to escape the helplessness, powerlessness, and pain due to incarceration itself. The suicidal deaths of C.J. and C.B. are a serious indictment of the institutionalized violence children face as prisoners of the Canadian state. It is disgraceful that in $21^{\text {st }}$ century North America, children are locked up in cages, far away from their families and communities, and punished and brutalized with inhumane treatment. That the prison environment itself is suicidogenic is erased in the inquest, which positions the institution, system and its agents as blameless. The article highlights the need to examine criminal justice practices and policies, if Indigenous and youth justice is to be addressed and achieved.

Nicole Schott, Lauren Spring and Debra Langan examine how performance ethnography is an important tool for critiquing - and extending the conversation about - the pathologization of girls and women who identify as pro-anorexia and pro-bulimia (ana/mia) on internet websites. The so-called 
mental illness of eating disorders is linked to the social promotion of gendered body images; yet, in the psy literature it is reduced to the individual failings of women and girls. The pathologizing of pro-ana and pro-mia identities unfairly ignores the influence of social structural factors in the relationship between feminization, embodiment, eating patterns and body image in patriarchal culture. The authors argue against psychocentricity that privileges the expert view. They advocate for a social justice approach that acknowledges the collective meanings of eating and body image issues for those who identify as anorexic or bulimic and for women and girls more generally who are immersed in a fat-phobic culture.

The article on homelessness written by Erin Dej provides an important case study of some of the ways psychocentrism manifests among a socially oppressed and excluded population. She demonstrates that homeless individuals are simultaneously pathologized and responsibilized through psychocentric discourses. According to her research, homeless individuals are expected to exhibit signs of shame, gratitude, deference, atonement and guilt in order to present the self as remorseful to their superiors, the agents of the homeless industry. Narratives provided by those struggling with economic inequalities displayed self-criticism rather than social criticism, and little selfcompassion. Their status as economically and materially poor becomes individualized as a symptom of mental illness and/or addiction seen as personal rather than social failures.

Certain analytical threads are woven throughout the special issue: first, psy experts exercise power in the construction of knowledge that medicalizes and pathologizes what are ultimately social and cultural values and practices; second, expert discourses encourage users or subjects to locate "pathologies" inside themselves rather than a result of social processes, structures and experiences; third, expert discourse denies, trivializes or minimizes the importance of social factors and social relations at play in pathologies; and fourth, expert psy discourses distract from wider structural issues of social injustice.

\section{Conclusion}

Social inequalities lead many to experience marginalization, inferiorization and stigma, all of which are bad for human health and thus counter to living a healthy, meaningful and rewarding life. It is thus incumbent upon us to become aware of discourses and practices operating within and across systems of domination that blame individuals rather than highlight the many socially-based mental and emotional problems experienced by members in our communities. Social justice approaches to mental health call on us to imagine and work towards alternative approaches to dominant biomedical discourses and practices as a public health issue and basic human right. 
Neoliberal societies justify retrograde social policies that were meant to provide a safety net for the vulnerable, but which are facing systematic dismantling today. This can be witnessed in minimal or decreasing investments to education, housing, healthcare and social services, while increasing public spending in support of militarism, corporate welfare, the formation of a police state, deepening local and global inequalities, and ecocidal industrial practices. Psychocentricity prevents, omits, erases, and negates the ability to understand how political and social structures, discourses and practices impact individual lives physically, materially, emotionally, mentally - and crucially - unequally in modern society. This special issue hopes to make these explicit and implicit connections between the personal and the social.

The appeal of psy promises and fixes are the effects of an inescapably therapeutic culture that pacifies the population by promoting individualized explanations for socially-based problems. The imperatives of governmental policies to ensure basic essentials for the vulnerable would be a good starting point for improving mental and emotional health of the population. Provisions of universal healthcare, educational opportunities for all, and social housing thus fall to the wayside as psy hegemony increasingly colonizes neoliberal culture. Consequently, if one experiences mental and emotional distress, one is compelled to find the problem within the self.

Analyzing psychocentricity entails critiquing the psychiatrization of everyday life that often produces or masks the social, economic, political and historical bases of human pain, trauma, and struggles. It also means attending to mental and emotional distress as a significant public health issue. The problem of psychocentrism is a key challenge to addressing contemporary pain, suffering and vulnerability, as it is difficult to imagine how human wellbeing can ever be promoted in a meaningful manner without addressing the larger social, cultural, economic, and political factors that shape human relations and experiences. It is my hope that the articles presented herein will assist in starting the long overdue conversation on mental and emotional distress as a significant social justice problem.

\section{Acknowledgments}

I would like to thank Guy Normand, Kimberley Ducey, and Elly Van der Zande for their mental and emotional support while working on this special issue.

\section{References}

APA (American Psychiatric Association). (2013). Diagnostic and statistical manual (DSM-5). Washington: American Psychiatric Association. 
Epstein, R. (2016). The empty brain. Aeon. Retrieved June 3, 2016, from https://aeon.co/essays/your-brain-does-not-process-information-and-it-is-not-a-computer

Foucault, M. (1954). Mental illness and psychology. Berkeley, CA: University of California Press.

Foucault, M. (1988). Madness and civilization. New York: Vintage Books.

Franklin, U. M. (2014). Ursula Franklin speaks: Thoughts and afterthoughts. Montréal: McGillQueen's University Press.

Goffman, E. (1963). Stigma: Notes of the management of a spoiled identity. Toronto: Simon \& Schuster.

Healy, D. (2012). Pharmageddon. Berkeley, CA: University of California Press.

Kirk, S. A., Gomory, T., \& Cohen, D. (2013). Mad science: Psychiatric coercion, diagnosis, and drugs. New Brunswick, NJ: Transaction Publishers.

Mills, C. W. (1959). The sociological imagination. New York: Oxford University Press.

Moncrieff, J. (2009). The myth of the chemical cure: A critique of psychiatric drug treatment. London: Palgrave MacMillan.

Noll, R. (2011). American madness: The rise and fall of dementia praecox. Cambridge, MA: Harvard University Press.

Pilgrim, D. (2003). Critical concepts in mental health. New York: Sage.

Pilgrim, D. (2005). Defining mental disorder: Tautology in the service of sanity in British mental health legislation. Journal of Mental Health, 14(5), 435-443.

Rimke, H. (1997). (Re)constructing the ethical self: Self-help literature as a contemporary project of moral regulation (Unpublished master's thesis). Carleton University, Ottawa, Canada.

Rimke, H. (2000). Governing citizens through self-help literature. Cultural Studies, 14(1), 61-78.

Rimke, H. (2003). Constituting transgressive interiorities: $19^{\text {th }}$ century psychiatric readings of morally mad bodies. In A. Arturo (Ed.), Violence and the body: Race, gender and the state (pp. 403-428). Bloomington, IN: Indiana University Press.

Rimke, H. (2005). Ungovernable subjects: A radical genealogy of moral insanity (Unpublished doctoral dissertation). Carleton University, Ottawa, Canada.

Rimke, H. (2010a). Consuming fears: Neoliberal in/securities, cannibalization, and psychopolitics. In J. Shantz (Ed.), Racism and borders: Representation, repression, resistance (pp. 95-113). New York: Algora Publishing.

Rimke, H. (2010b). Beheading aboard a greyhound bus: Security politics, bloodlust justice, and the mass consumption of criminalized cannibalism. The Annual Review of Interdisciplinary Justice Research, 1, 172-192.

Rimke, H. (2010c). Remembering the sociological imagination: Transdisciplinarity, the genealogical method, and epistemological politics. International Journal of Interdisciplinary Social Sciences, 5(1), 239-254.

Rimke, H. (2011). The pathological approach to crime: Individually based theories. In K. Kramar (Ed.), Criminology: Critical Canadian perspectives (pp. 78-92). Toronto: University of Toronto Press.

Rimke, H. (2012). Securing injustice: The psychocriminalization of resistance as 'political violent extremism.' The Annual Review of Interdisciplinary Justice Research, 3, 26-39.

Rimke, H. (2016). Pathologizing resistance and promoting anthropophobia: The violent extremism risk assessment (VERA) as case study. In H. Ramadan \& J. Shantz (Eds.), Manufacturing phobias: The political production of fear in theory and practice (pp. 17-26). Toronto: University of Toronto Press.

Rimke, H., \& Brock, D. (2012). The culture of therapy: Psychocentrism in everyday life. In M. Thomas, R. Raby \& D. Brock (Eds.), Power and everyday practices (pp. 182-202). Toronto: Nelson.

Rimke, H., \& Hunt, A. (2002). From sinners to degenerates: The medicalization of morality in the 19th century. History of the Human Sciences, 15(1), 59-88.

Smith, D. E. (1987). The everyday world as problematic: A feminist sociology. Boston: Northeastern University Press.

Smith, D. E. (1990). Texts, facts, and femininity: Exploring the relations of ruling. London: Routledge. 
Szasz, T. (2003). Pharmacracy: Medicine and politics in America. New York: First Syracuse University Press.

Turner, R. E., \& Edgley, C. (1983). From witchcraft to drugcraft: Biochemistry as mythology. Social Science Journal, 20(4), 1-12. 